The University of San Francisco

USF Scholarship: a digital repository @ Gleeson Library |

Geschke Center

Economics

College of Arts and Sciences

$1-2-2016$

\title{
Wheels of Fortune: The Economic Impacts of Wheelchair Provision in Ethiopia
}

Justin L. Grider

jlgrider@usfca.edu

Bruce Wydick

University of San Francisco, wydick@lucas.usfca.edu

Follow this and additional works at: http://repository.usfca.edu/econ

Part of the Accessibility Commons, and the Economics Commons

\section{Recommended Citation}

Grider, J., Wydick, B. Wheels of fortune: the economic impacts of wheelchair provision in Ethiopia (2016). Journal of Development Effectiveness, 8 (1), pp. 44-66. http://dx.doi.org/10.1080/19439342.2015.1064986

This Article is brought to you for free and open access by the College of Arts and Sciences at USF Scholarship: a digital repository @ Gleeson Library | Geschke Center. It has been accepted for inclusion in Economics by an authorized administrator of USF Scholarship: a digital repository @ Gleeson Library | Geschke Center. For more information, please contact repository@usfca.edu. 


\title{
Wheels of Fortune: The Economic Impacts of Wheelchair Provision in Ethiopia
}

\author{
(JEL Codes: I15, I31, I32, 012, 015, 022)
}

Key Words: Wheelchairs, Disabilities, Program Evaluation, Treatment Effects, Time Allocation

\author{
Justin Grider*
}

Bruce Wydick***

June 16, 2015

\begin{abstract}
Although approximately 1 billion people in the world live with physical disabilities, there is a lack of rigorous research on the economic impacts of providing assistive devices for persons with disabilities. Our study involves 261 people with disabilities in Addis Ababa, Ethiopia, where 121 had received wheelchairs donations via non-profit organizations. Using covariate matching, seeming unrelated regressions (SUR), and a series of robustness checks for endogeneity, we find those given access to a wheelchair allocated 1.75 more hours per day to work, 1.40 fewer hours per day to street begging, and realized a $77.5 \%$ increase in income. Results point to a $122 \%$ internal rate of return based on new income created from wheelchair donation.
\end{abstract}

*Monitoring and Evaluation Fellow, Village Enterprise, e-mail:jgrider15@gmail.com.

**Professor of Economics and International Studies, University of San Francisco, San Francisco, CA 94117. Distinguished Research Affiliate, Kellogg Institute of International Studies, University of Notre Dame, e-mail: wydick@usfca.edu. We thank Sherefedin Nuri, John Maxwell, and Joseph Ahlijah for help with this research. Funding from the University of San Francisco's graduate program in International and Development Economics and the Faculty Development Fund is gratefully acknowledged. An earlier version of this paper was the first-place winner of the 2014 New Economic Talent Competition and Conference hosted in Prague, Czech Republic. We also thank the organizers and the participants in this conference for the award and for helpful comments on the paper. 


\section{Introduction}

The World Health Organization reports that there are approximately 1 billion people living with disabilities in the world today. Among the physically disabled in the developing world in need of assistive devices, only 5-15 percent have access to them. There are an estimated 65 million people with disabilities in need of a wheelchair (WHO, 2013), most of these individuals living in developing countries. We examine the economic impacts of wheelchair provision to a subset of this population in a study of 261 individuals living with walking disabilities in Ethiopia.

Disability and poverty are closely linked around the world, and people who are disabled are strongly and disproportionally present among the world's poor. Disabilities appear disproportionally among the poor for two main reasons: 1) In-utero conditions, nutrition, and working conditions are less favorable, resulting in a greater rate of disability among the existing poor; and 2) Disabilities in themselves frequently cause people to become poor. The World Health Organization defines disability as an umbrella term for impairments, activity limitations and participation restrictions (2013). Data show that individuals with disabilities consistently have lower incomes, higher poverty rates, and they are far more likely to be unemployed than people without disabilities (Mitra et al., 2013; Pagan, 2013), especially in the developing world. Although many poor people with a disability in the developing world lack access to assistive medical devices, substantial efforts exist among many donors, such as Rotary International, World Vision, Global Wheelchair Mission, Limbs for Life Foundation, and the United Nations Children's fund to make these devices available. But there has been a dearth of research documenting the extent to which assistive devices help to re-integrate those with disabilities in the developing world into normal economic life, empower them to become economically self-sufficient, and allow them to participate with dignity alongside the nondisabled in their respective societies.

The research in this paper evaluates the economic impacts of wheelchair donations for the physically disabled in Addis Ababa, Ethiopia. There are an estimated 15 million children, adults and elderly persons living with disabilities in Ethiopia (International Labour Organization, 2013). Wheelchair donations seek to improve economic, societal, and personal outcomes for those without use of their legs, by allowing them greater mobility, which may impact a variety of economic outcomes. But to this point, there has been no rigorous econometric analysis of the impacts of providing wheelchairs for those with a disability in the developing world. Because of the ethical issues involved in experimentation with assistive 
devices such as wheelchairs, we use matching models to estimate wheelchair impacts on mobility, and the impact on time-allocation of persons with a disability away from street begging and toward income-generating activity; we also estimate impacts on their earned income. Our results point to large impacts from wheelchair provision on mobility, employment, and income. Indeed we find significant time reallocation away from begging (1.40 fewer hours per day) and toward income-generating activity (1.75 more hours per day) and $77.5 \%$ higher income. These results are extremely encouraging, and point to the vast unrealized potential within the communities of those living with disabilities in developing countries such as Ethiopia. Yet in light of the relatively small scope of our study we view the major contribution of this paper to be an invitation and encouragement for further impact studies on similar interventions, both those that expand the subject pool, and those that ascertain external validity to other countries--and even to other types of disabilities. New studies should search for quasi-experimental methods that allow for rigorous identification of treatment effects while respecting the ethical boundaries to experimentation in such a sensitive area.

The remainder of the paper will proceed as follows: Section 2 reviews some of the impact literature on disability interventions. Section 3 introduces the data and methodology and introduces the model used to obtain our estimation results. Section 4 interprets the results, provides robustness checks, and our cost-benefit analysis. Section 5 summarizes our results and presents recommendations for future research.

\section{Development and disabilities}

There is growing evidence that failure to address the needs of those living with disabilities significantly constrains economic development. Metts (2004) concludes, for example, that Ethiopia loses between $\$ 598$ and $\$ 779$ million from its GDP of only $\$ 6.1$ billion (2004) from not effectively addressing disability in the country. Awan (2012) studies the potential productivity gains from socio-economic health policies targeted for the blind population in Pakistan. The study uses the average wage rate and appropriate discount factors to show that if the disabilities of the blind population in Pakistan were addressed, it would result in a total increase in GDP of $\$ 4.9$ billion over a period of ten years.

The relationship between disability and poverty is clearly endogenous, but there have

been several efforts to empirically evaluate disability programs, including Gannon (2005) in Ireland, Contreras et al., (2006) in Chile and Uruguay, and Trani et al., (2012) in Afghanistan 
and Zambia. Looking at sixty-nine countries through a standardized WHS measure of disability and employment rates, Mizunoya (2012) shows a disability gap in employment rates in developing countries. Mitra, et al. (2012) carry out a multidimensional study of disability and poverty across the developing world. They find that persons with disability, on average, experience multiple deprivations at higher rates and in higher breadth, depth and severity than persons without disabilities.

Many previous studies do not clearly establish causal effects from disability interventions, but nevertheless hint at significant impacts of assistive devices. Tolerico (2007) uses survey data and a custom data $\log$ to investigate the mobility characteristics of fifty-two manual wheelchair users in the residential setting over the long term; showing that the average daily distance covered was approximately 3,400 meters, far greater than possible without the device. Yet these results are purely descriptive, and they use a small sample with no control group. Pagan (2013) investigates how people with disabilities allocate their time to daily activities as compared to their non-disabled counterparts. Using micro-data with over 20,000 observations from the Spanish Time Use Survey (STUS), Pagan uses a simple OLS model to show non-disabled males devote 87.95 more minutes to market work, while non-disabled females devoted 57.81 more minutes than their counterparts.

Shore (2012) studies health and lifestyle changes brought about by wheelchair provision through the framework of the World Health Organization's International Classification of Functioning, Disability and Health (ICF). Partnering with Free Wheelchair Mission, Shore obtains data from 600 wheelchair participants throughout India, Chile and Vietnam. The participants of the study were given a survey upon receiving a wheelchair and then were resurveyed 12 months later. The participants were informed that the purpose of the survey was to evaluate how the wheelchair affected their health and well-being. The lifestyle questions, taken from the ICF, used an ordinal scale to evaluate the level of difficulty when performing certain activities. Recipients reported less personal illness, less hospitalization, increased mobility and diminished pain. All of the results are summary in nature and no effort was made to identify a comparison group, making causal inference difficult. Nonetheless the surveys highlight the improvement in psychological well-being and quality of life during the 12-month period of wheelchair use: The number of people who felt that life was "fairly good" or "great" increased from 12.6 to 63.6 percent after receiving the wheelchairs. Coefficients for variables measuring dependence decreased as did the percentage of participants that never left the home from 46.6 to 22.4 percent. 
Borg et al. (2012) study the existence of a possible relationship between use of assistive technologies and enjoyment of basic human rights in low-income countries. The study focuses on assistive technology in the form of hearing aids and wheelchair provisions for the respective participants. They use cross-sectional data in Bangladesh to study impacts on standard of living, health, education and work. Their results show that wheelchairs increased mobility, but they found little difference in physical and mental health as well as a negative association between wheelchair use and working status. Yet wheelchair users reported less mobility difficulty compared to non-users, and, after adjusting for physical accessibility to the work place, they felt that they were more likely to enjoy the right to work. Borg et al. (2012) mention that the results should be interpreted cautiously, due to statistical over-fitting. Moreover, the lack of a clear counterfactual prevents one from ascribing causal effects to the intervention.

Shore (2008) surveys 188 wheelchair recipients in India and Peru who had used a wheelchair for the previous 33-month period. Beneficiaries were asked for feedback on reliability, wheelchair maintenance, health, maneuverability and comfort in wheelchairs. Surveying after this more protracted length of wheelchair use allows for a wider timeframe that allows for the user to become more accustomed to the use of a wheelchair. The survey conducted was more open-ended in nature, which allowed for interpretation by the recipient and only summary statistics are available on quantitative measures, which yielded no statistical significance.

Other studies have focused on the use of wheelchairs among beneficiaries-why a wheelchair may or may not be used after it has been provided. For instance, Mukherjee (2005) analyzes the fate of donated wheelchairs in West Bengal. Wheelchair recipients were divided into two groups, regular users and occasional users. The two groups were monitored physically and then asked two basic questions regarding usage of the donated wheelchair. If the wheelchair was rejected, follow-up questions were asked as to why. The study yielded surprising findings. Out of 162 past wheelchair recipients from various NGOs, the data showed that 71.6 percent of the wheelchairs (116 out of 162 wheelchairs) were not used or were sold. The main reasons given for wheelchair abandonment were pain or fatigue with use and the lack of habitat adaptability of wheelchairs.

We believe that studying wheelchair provision through a development economics lens rather than a disability lens brings at least two advantages. First, it helps to move the debate about the provision of assistive devices away from charity and toward economic impacts that may substantially exceed the cost of an intervention--even apart from the physical, psychological, and social benefits assistive devices bring to recipients. Second, while it is clear 
that a number of studies have been carried out on wheelchair users, previous studies lack the ability to generate clear counterfactuals, making causal inference on assistive device interventions challenging. Because previous research has lacked the ability to make causal statements on economic outcomes, there has existed no clear basis for policy interventions that might validate the provision of these devices even purely from an economic standpoint. Our study takes one modest but important step to begin to fill this gap.

\section{Data and methodology}

\subsection{The data}

Our data was collected from a first-hand survey administered in June-August of 2013 in cooperation with three non-governmental organizations that work with people with disabilities throughout the region in and surrounding Addis Ababa, Ethiopia. Cheshire Services, POC, and Addis Guzo are organizations that seek to provide rehabilitative services and orthopedic devices to clients. The data collected comes from a cross sectional survey of 261 individuals identified by wheelchair recipient lists and waitlists from Cheshire, POC and Addis Guzo. Physical disabilities in the sample include polio, infections, work accidents, war victims, muscular dystrophy and leprosy. Every individual in the sample had been seen by a physician and had been deemed physically in need of a wheelchair.

Wheelchairs do not last indefinitely, and their functionality depreciates with extensive use, especially in rough terrain of the developing world. (See studies in Mexico by Toro et al. (2012) and in rural West Bengal by Mukherjee et al. (2005)). In our study, 120 individuals currently had use of a donated wheelchair from one of our three partner organizations. Of the 141 non-wheelchair users in the sample, 58 used to have a wheelchair in the past but currently did not. Of these, 31 self-reported that they did not have a wheelchair because the old wheelchair had broken and was no longer serviceable. The other 27 of these reported that they had either lost their wheelchair, that they had to sell it, or reported that it had been stolen. The remainder of the control group includes 66 on an official waitlist to receive a wheelchair for the first time and 17 who were deemed to be qualified for a wheelchair, but had not yet been placed on the official waitlist. The final sample size of 261 is the result of locating every person on the current and future wheelchair recipient lists provided by each organization. Thus our study is essentially a pipeline study, but where some of the future wheelchair recipients also had access

to a wheelchair in the past. We will discuss how the possible existence of correlated unobservables in any of these groups might affect our estimates. 


\subsection{The allocation of wheelchairs}

This study uses a control group of non-wheelchair users, statistically similar to wheelchair users over observable covariates, but on the list of qualified recipients for a wheelchair in the future. For our impact estimates to remain unbiased, it must account for individuals self-selecting to be among the first to receive a wheelchair. This study does not contain multiple cross sections and cannot control for unobserved heterogeneity, but multiple approaches are used to elucidate the possible presence of endogeneity and relationship between the error terms corresponding to treatment and impact, including the use of prior wheelchair recipients who no longer possess one.

We surveyed social workers, physicians and employees at Cheshire, POC and Addis Guzo to evaluate how wheelchair allocation took place. The organizations provide wheelchairs at no cost to whomever qualifies for them; they do not withhold wheelchairs based on religion, sub-city or any other factors. Addis Ababa has 11 sub-cities within the city limits. Within each sub-city, a social worker from the Bureau of Labour and Social Affairs (BOLSA) works to locate individuals with physical disabilities. Social workers try to connect people with physical disabilities with organizations, like our partner organizations, which have trained physicians who evaluate each potential beneficiary. Cheshire, Addis Guzo, and POC only have two criteria for wheelchair donation: the first is a physician's note deeming an individual physically in need of a wheelchair; second, the organizations need to have a wheelchair available of appropriate fit for the individual. Every subject in our study was examined by a physician and deemed physically disabled to the point of needing a wheelchair. Donated wheelchairs were of varying types even within each organization and often rebuilt from previously donated wheelchairs.

Because treatment of a wheelchair is a proven medical device, randomization of wheelchairs fails to satisfy the essential equipoise criteria for randomization of a treatment and does not pass ethical criteria in the treatment of human research subjects. Thus our study necessarily uses observational rather than experimental data, comparing current activity of those who have received a wheelchair from one of our three partner organizations, and are currently using the wheelchair, to those who have been medically qualified to receive a wheelchair in the future from one of these organizations. This requires close attention and scrutiny to control for prospective ex-ante differences between wheelchair beneficiaries and non-wheelchair users. The key assumption is that assignment to treatment be orthogonal to potential outcomes, the ignorability assumption necessary for statistical matching methods to estimate causal effects from treatment. 
We carried out interviews with staff to ascertain whether the order of allocation of the wheelchairs appeared to be related to potential outcomes. This exercise revealed allocation to be substantially orthogonal to impact variables in our judgment, at least creating a case for the use of matching methods to generate estimates of causal effects. We exploit the presence in the sample of those who received a wheelchair in the past, but no longer have it, to help control for possible self-selection of order issues that might bias parameter estimates. Also of potential concern would be the presence in our sample of a relatively small, but undetermined number of individuals who had sold their donated wheelchairs. But because selling the wheelchair is likely to be correlated with a lesser need for the wheelchair, this would actually generate a downward bias in our estimates. So to extent that sale of wheelchairs creates bias in our estimates, it would turn our estimates into a lower bound on positive impacts from the wheelchairs. We carry out Rosenbaum bounds tests to ascertain the level of endogeneity from any of these sources that would render our estimates invalid.

\subsection{Pictorial time survey}

The survey we implemented included fifty-five questions plus a time survey (Figure 1). Our time survey uses a pictorial-journal approach, which better isolates exact time use throughout a given day. The survey methods are a mixture of both the Melina Method and the Participatory Rural Appraisal (PRA) method, used by Masuda et al. (2012) to measure time use in rural Ethiopia from the impact of water provision. The enumerators asked everyone in the sample about their previous days' activities in 30 minute segments. The time survey includes 19 pictures and descriptions of the depicted activities in a box on the top of the sheet with a letter corresponding to each picture. Time is split up into 30 minute segments for a 24 hour period. With only 1440 minutes in a day, each participant has the same amount of time to allocate to various activities performed throughout the day.

Each participant indicates the correct letter that corresponds to the picture performed at a given time (e.g. the letter $A$ is matched with going to school). The time survey interviews took place Tuesdays through Saturdays, asking participants about the previous day to isolate activities to within the week. We sought a direct time comparison across all subjects in our sample, aggregating exactly how each individual allocated his or her time over the previous day. Any changes and influences in time allocation through a wheelchair may translate into economic productivity and personal welfare, whether it be through work, shopping or other activities. 


\subsection{Methodology}

Our impact identification strategy relies on creating an "as good as random," wellidentified control group that can be compared to wheelchair users. Measuring the average treatment effect on the treated without bias requires the conditional independence (ignorability) assumption: $Y_{0}, Y_{1} \perp T_{i} \mid X_{i}$ with $Y_{1}$ representing the outcomes under treatment status, $Y_{0}$ being the outcome for individuals under non-treatment status, $T_{i}$ indicating treatment status, and $X_{i}$ being a vector of observable controls not affected by the treatment of receiving a wheelchair. In this we employ a variety of covariate and propensity score matching estimators. Matching strategies either match units directly on observed covariates or use a composite score (Steiner 2010) and then perform a test of difference in means in the impact variable between the two samples.

Propensity score matching (PSM) uses the probability of a unit belonging to the treatment group based on propensity for treatment derived from a probit estimation, and it matches a treated observation with one or more similar propensity score observations in the control group. Covariate matching (CVM) creates the closest Euclidean distance over an interval between a treatment and control observation. Both rely on a conditional independence assumption, matching on covariates that do not change with treatment status, and on an overlap between matching variables between treatment and control groups. PSM is a common estimator but because of the non-linearity of the probit and logit functions used to estimate the propensity scores, Imbens (2004) suggests that it may yield unreliable standard errors. As a result we also use nearest-neighbor covariate matching. CVM of course does not control for selection bias, but does generate standard errors that can be estimated more reliably. We use the following covariates to created matches between the treatment and control groups: age, gender, education, amount of time disabled, number of siblings, religion, and type of disability. The outcome variables we explore are mobility, in the form of farthest distance traveled in the past week, time allocated to working in an income-generating activity, time allocated to street begging, probability of employment, and weekly income received from any source. Across these variables, we are interested in the average treatment effect on the treated (ATT):

$$
\mathrm{ATT}=\mathrm{E}\left(Y_{1} \mid T=1\right)-\mathrm{E}\left(Y_{0} \mid T=1\right)
$$

Equation 1 above for the ATT is the difference in the outcome variables between treatment and non-treatment for those who received a wheelchair. It is the average effect of treatment on those subjects who receive treatment. In contrast, the ATE is the average effect, 
at the population level, of moving an entire population from untreated to treated. But the second term in (1) is not observable. We cannot observe the same individual receiving and not receiving treatment. What is observed is

$$
\mathrm{E}\left(Y_{1} \mid T=1\right)-\mathrm{E}\left(Y_{0} \mid T=0\right)
$$

It is well known that by adding and subtracting the counterfactual, $Y_{0} \mid T=1$, the difference between $Y_{1} \mid T=1$ and $Y_{0} \mid T=0$ is the ATT plus the selection bias as shown below.

$$
\left[\mathrm{E}\left(Y_{1} \mid T=1\right)-\mathrm{E}\left(Y_{0} \mid T=1\right)\right]+\left[\mathrm{E}\left(Y_{0} \mid T=1\right)-\mathrm{E}\left(Y_{0} \mid T=0\right)\right]
$$

In our context, selection bias could take the form of more highly motivated individuals being selected first (or self-selecting first) for wheelchair assignment. Note that if $\mathrm{E}\left(Y_{0} \mid T=1\right)>\mathrm{E}\left(Y_{0} \mid T=0\right)$, the counterfactual outcomes of these individuals are higher and would result in an over-estimation of impact. Selection bias moves to zero in our study assuming that order of treatment is independent of potential outcomes. Without randomization, matching is applicable and used here with the assumption that only observed characteristics affect program participation, or receiving a wheelchair. This ignorability assumption between treatment and control allows for comparison in outcomes over a set of observables between the two groups.

While PSM matches on probability of assignment to treatment based on probit estimations, CVM matches on nearest Euclidean distance over the vector of covariates so that nearest neighbor matching finds the closest Euclidean distance of a non-treated observation to a treated observation. We carry out nearest-neighbor CVM over the nearest 4 neighbors $(m=4)$ with replacement to reduce expected variance.

Because matching involves a number of assumptions, other econometric techniques are also used as checks. Rosenbaum bounds tests are used with our PSM estimates to help measure the impact of selection bias on our estimates by calculating how large the presence of endogeneity bias must be in order to render our estimated impacts statistically invalid.

We also use standard regression to obtain an alternate set of effect estimates, and where censoring is present in the outcome variables, we employ Tobit and Heckman estimators. We also present Seemingly Unrelated Regression (SUR) estimates as a check on our time allocation estimates, where SUR exploits covariation in the error terms over a set of regressions, clearly present when total time allocation must sum to unity. Of course these additional estimation techniques do not solve potential endogeneity issues, but they do provide a valid check and an opportunity to see how robust the results are to different specifications and methodologies. 
The regression model that we estimate is

$$
Y_{i}=\beta_{0}+\beta_{1} T_{i}+\beta_{2} P_{i}+\boldsymbol{\beta}_{3} \boldsymbol{X}_{\boldsymbol{i}}+\varepsilon_{i}
$$

where $Y_{i}$ is the dependent variable (either the number of hours worked per day, the farthest distance traveled the past 7 days (measured in kilometers), number of days left the house,

probability of being employed, or the amount of weekly income received (measured in USD) for an individual $i$ ), $T_{i}$ is a treatment dummy variable for currently using a wheelchair at the time of the interview, $P_{i}$ is a dummy variable if an individual was allocated a wheelchair in the past but does not currently possess one, and $\boldsymbol{X}_{\boldsymbol{i}}$ is a vector of control variables used, and $\varepsilon_{i}$ is the error term. Given the assumption that losing a wheelchair is random and orthogonal to potential outcome variables, $\beta_{1}$ yields the ATT of having a wheelchair.

\section{Results and data analysis}

Table 1 presents the summary statistics over treatment and control groups. Preexisting covariates: age, the number of children, the number of siblings, disability type and marital status are measured for both treatment and control groups, given by simple means tests. The table indicates that most of the preexisting covariates are not statistically different between the treatment and control groups. One notable difference is years of schooling, where those with wheelchairs have about a year and a half more education on average. A simple means test between the treatment and control groups show that ambition, the number of days a person left the house, time spent working, the probability of having a job, farthest distance traveled, weekly income and the number of years of schooling are all significantly more for wheelchair users, compared to non-wheelchair users. All variables that could be affected by the wheelchair are quite different between the treatment and control groups. The treatment group travels 12.56 kilometers farther, spends over two hours more working, has a 20 percent higher probability of having a job, has almost 2 more years of schooling and $\$ 6.69$ more per week than the control group. Figures 1-6 show differences in means and density functions between treatment and control for time working, income, and farthest distance travelled.

\subsection{Matching results for current wheelchair users}

The results from matching show both the average treatment effect of a wheelchair (ATE) and the average treatment effect of a wheelchair on those who were provided a wheelchair (ATT). Nearest neighbor covariate matching estimates the ATT and ATE on the 
dependent variables by comparing outcomes between treated and control observations across observable covariates. The difference between the ATT and the ATE is that the estimates are either for the treated observations (ATT) or for the sample as a whole (ATE). For example when estimating the ATE on weekly income, all observations are matched to their nearest $m$ neighbors of the opposite treatment group; when estimating the ATT, only the treated are matched. Table 2 shows results from the entire sample, matching a current wheelchair user to a non-wheelchair user in the sample. (Sections 4.2 and 5.3 break the sample size down further to compare past wheelchair users, those who have never used a wheelchair before but are in need of one, and current wheelchair users.)

Looking at the average treatment effect on the treated using covariate matching to the nearest 4 neighbors, Table 2 shows that current wheelchair users spend 1.75 more hours working per day and earn $\$ 6.23$ more per week, a $77.5 \%$ increase compared to matched individuals that are disabled without current wheelchair access. Wheelchair beneficiaries are also 15.1 percentage points more likely to be formally employed compared to the control group, significant at the 1 percent and 5 percent level respectively. Based on the ATT, wheelchair beneficiaries travel 11.18 kilometers farther from their homes in a week than the control group, but only the ATE is statistically significant with an estimate of 14.47 kilometers farther. The possibility of other transportation options may play a role in the impact from the wheelchair in terms of distance traveled. Taxis, buses and private vehicles can all be taken by both wheelchair and non-wheelchair users. Moreover, wheelchairs facilitate travel over relatively shorter distances, but also can be inconvenient when using public transportation. The results clearly reject a null hypothesis of no impact on time allocated to work, probability of employment, and weekly income. It appears that wheelchairs exhibit nontrivial impact on beneficiaries; point estimates are not only significant, they are quite large.

As a check on our CVM results, we also include PSM results in Table 3 (and the estimation of the propensity scores in Table 4), which are very similar, but slightly larger in magnitude and significance than the results from CVM. PSM results show the difference in means between treatment and control groups to be quite substantial for the outcome variables we measure. Wheelchair beneficiaries earn $\$ 7.44$ more a week, are more than 20 percent more likely to be employed and work over 2.20 hours more each day compared to the control group, each significant at the 1 percent level. PSM results also show that the farthest distance traveled by wheelchair beneficiaries is 12.37 kilometers farther in a week than non-wheelchair users, significant at the 5 percent level now. The difference between means for beneficiaries and non- 
beneficiaries is large and points to a necessity of strong assumptions in the selection process for treatment.

Higher weekly income is clearly linked to the greater amount of time devoted to income-generating activity each day. The empirical results support the theory of time allocation developed by Becker (1965), which stresses the importance of forgone earnings and its determinants on time allocation. Wheelchairs make leisure time more expensive and traditional work more productive than begging.

\subsection{Comparing past wheelchair users and current wheelchair users}

Table 5 is an alternative CVM results for past wheelchair users who currently are not using a wheelchair because the wheelchair was broken, stolen, lost, or possibly sold. Thus the comparison of means between matched pairs are the differences in outcomes of current wheelchair users compared to those in the sample who received a wheelchair in the past but no longer possess one. With this specification it is possible to ascertain the extent to which selfselection into early reception of a wheelchair drives results as well as testing if having a wheelchair in the past is enough to have an impact on current levels of income, distance traveled, employment status and time working. It is possible that simply receiving a wheelchair at some point in the past is enough to influence current outcomes.

Table 5 shows CVM results comparing current wheelchair users to past wheelchair users. Results show that current wheelchair users earn $\$ 4.31$ more each week and have a 15 percentage points greater probability of employment compared to past wheelchair users, significant at the 10 percent level. The results also show that current wheelchair users spend 1.77 hours more per day in income-generating activity and 1.50 fewer hours begging per day than past wheelchair users, significant at the 5 percent level, a nearly identical difference to the difference we estimate between wheelchair users and all non-wheelchair users. Finally Table 5 shows point estimates on differences in mobility also to be quite similar. Notably, the coefficient on time spent working and probability of employment is nearly the same magnitude as in Table 2 when the entire sample is used. The coefficient on weekly income in Table 5 is not as large as in Table 2, but remains significant at the $10 \%$ level.

Two points are clear from this analysis: The first is that the data show that there seems to be little adaptation in terms of employment for past wheelchair users. Beneficiaries must continue to own a functioning wheelchair to reap the benefits of the intervention. It appears that having had a wheelchair in the past is not enough to affect current employment status. The second is that these results indicate that the differences between matched wheelchair 
beneficiaries and non-beneficiaries appear unlikely to be accounted for by self-selection or problems of endogeneity. The difference between wheelchair beneficiaries and nonbeneficiaries is virtually the same as the difference between beneficiaries and those who had a wheelchair in the past, but no longer have one.

\subsection{Comparing past wheelchair users and non-wheelchair users}

As a further check on for endogeneity, we compare outcomes for past wheelchair users and those who have never used a wheelchair in the past but are in need of a wheelchair and will receive one in the future. Here all current wheelchair users are dropped from the sample. If the impacts we find are from having a wheelchair and not from self-selection, matching results should display little differences between these groups. Table 6 shows that past wheelchair users on average have higher weekly income of $\$ 3.25$ than those who have never had a wheelchair before, significant at the 10 percent level, but show no difference in the probability of employment. This difference in income could result from some latent characteristic of those who received a wheelchair in the past, or from advantages that have accrued in the past from having a wheelchair. However, there is no statistical difference in time spent working or street begging, distance traveled from house, or days left the house. The results for job, time working and distance traveled are not surprising; a person needs to be currently using a wheelchair to affect current levels of time, employment status and mobility. The major difference is in weekly income, indicating that past wheelchair users are plausibly pushed to increased income levels. A past wheelchair user may not have a higher probability of employment, but is able to get more income from what job they currently have, which may have been obtained when the subject owned a wheelchair. However, that we find no significant differences in time allocation and mobility between past wheelchair users and those who have never had a wheelchair provides added confidence that the ignorability assumption largely holds in our main estimation and that results are not driven by correlated unobservables.

\subsection{Robustness checks}

Based on our results in sections 4.2 and 4.3, we find little evidence that differences in wheelchair status are likely to be driven by endogeneity or self-selection issues. But we still might ask how much endogeneity in treatment would have to exist to render our matching

results invalid? To measure the effect on our estimates from different levels of endogeneity bias, we estimate Rosenbaum Bounds for the propensity score matching outcome variables. Rosenbaum Bounds calculated after PSM results, ascertain the level of self-selection on 
unobservables that would have to be present, if the unobservable perfectly determined the outcome variable, in order to make results statistically insignificant.

The Rosenbaum Bounds are estimated after the PSM results on time spent working in income-generating activity, weekly income, and farthest distance traveled in the past seven days. For weekly income, the bounds suggest that even with the presence of unobserved endogeneity that make those with this characteristic (causing them to be the first to receive a wheelchair and have higher incomes) 50\% more likely to be the first to receive a wheelchair, the PSM results are still valid (Table 7). In other words, assuming a factor imbedded in the error term that (nearly) perfectly predicts the impact variable is present among the treated, the treated would have to be $50 \%$ more likely to be selected to receive a wheelchair to render the impact insignificant (gamma in Table 7). The Rosenbaum Bounds of time spent working and farthest distance traveled the past week are smaller. For time spent working and farthest distance the Rosenbaum Bounds suggest that even with unobserved factors that make beneficiaries $20 \%$ and $10 \%$ more likely to apply to receive a wheelchair, the PSM results retain significance (Tables 8 and 9). Ideally one would like to have gamma as high as possible, but given the small sample size, these results are not surprising.

Matching shows significant results, but requires strong assumptions as well as using means instead of individual observed values to compare the treatment and control groups. For further robustness checks, we used various specifications of the linear regression model to estimate impacts. Table 10 shows the results of the Seemingly Unrelated Regression (SUR). Seemingly Unrelated Regression uses multiple valid linear regression equations for time allocation, but allows the errors to be correlated across the equations. Regressing time allocation to working, socializing, begging and other activities are all related, and SUR allows flexibility to the error terms between these regressions to be correlated. We are also able to display results from other time categories in this analysis. We group activities into four categories and control for a number of variables, and as shown in our regression specification, a dummy variable for if a person used to have a wheelchair in the past but currently does not. Results are quite similar to our matching results, where Table 10 shows that current wheelchair users spend 1.94 more hours per day working than non-wheelchair users, significant at the 1 percent level. Time begging is reduced by 1.20 hours and social time is reduced by 0.71 hours. Time out of the house increases by 0.18 hours, but is not significant. Estimating the differences in impact variables between those who have a wheelchair now and those who used to have a wheelchair (but do not now have one) controls for some self-selection that matching estimates perhaps do not-but results are very similar between the two methods. 
The OLS, Tobit, and Heckman estimations on weekly income in Table 11 are also similar to the matching results. The latter control for censoring of the income variable at zero because in the sample, there are a number of people who do not have any income, do not work at all, or have not traveled in the past week. This implies censoring at a lower bound of zero and the Tobit takes into account an unobservable latent variable that is potentially negative.

OLS estimation shows the income of current wheelchair users at $\$ 7.87$ more per week, while the Tobit estimation shows the treatment group earning $\$ 9.45$ more per week, significant at the 1 percent level (Table 11). The Heckman estimation yields a similar point estimate, but a larger standard error renders the point estimate insignificant. The dummy variable for having a wheelchair in the past (but not currently) has a coefficient of $\$ 1.86, \$ 2.96$, and $\$ 1.31$ for the OLS, Tobit, and Heckman estimations respectively, but none of these are significant. Table 12 shows similar estimates to our matching models from OLS, Tobit, and Heckman estimations on farthest distance traveled. Tables A1, A2, A3, and A4 in the Appendix online present OLS estimations on all of our impact variables with additional controls, finding little change in point estimates.

\subsection{Cost-benefit analysis}

Using our conservative covariate matching estimates for the average treatment effect on the treated (ATT), a current wheelchair user realizes a $\$ 6.23$ per week increase in income over a matched subjects without access to a wheelchair. In Table 13 we present a simple cost-benefit analysis that takes into account only these income changes and the cost and servicing of the wheelchair. The $\$ 6.23$ multiplied over one year results in an added \$324 per year for wheelchair users. Our partners report that it costs approximately $\$ 500$ to provide a wheelchair to a person who is physically disabled in Addis Ababa. Assuming that the wheelchair lasts three years before it needs to be replaced, a discount rate of 10 percent, and repair costs of $\$ 20$ after one and two years, a wheelchair produces a net present value of $\$ 352.84$ with an internal rate of return at $122 \%$ over its serviceable life. Thus even if wheelchair recipients were to finance the purchase of a wheelchair through a microloan or other type of program, our results show that such a program would yield large and significant benefits to program participants even at relatively high rates of interest. Free distribution of the wheelchairs, as is carried out by the non-profits in our study realizes an equally high social rate of return, simply shifting more of the benefits to wheelchair recipients. 


\section{Discussion and conclusion}

What are the economic impacts of wheelchair distribution to people with a physical disability? Our study using data from Ethiopian subjects suggests that impacts on economic activity are large and statistically significant. Our study is based on a modest sample, but the results we find are encouraging and warrant further research to assess their external validity. The impact of interventions for people with various physical disabilities is an area that has yet to be studied rigorously in the development economics literature.

This study analyzes the question through data collected from 261 physically disabled individuals, 120 of whom were wheelchair recipients and 141 of whom were qualified to receive one in the future. Using nearest neighbor covariate matching methods, we find that wheelchair beneficiaries on average work 1.75 added hours per day, spend 1.40 fewer hours per day street begging, and earn $\$ 6.23$ more per week than a control group of similarly matched nonwheelchair users who are in need of a wheelchair. Our results are robust to different types of estimation and to any modest level of endogeneity, although we find little evidence for it. Our results comparing current wheelchair users with those who gained access to a wheelchair in the past, but no longer possess one, show similar differences in mobility and time allocation as our main estimation. In contrast, past wheelchair recipients show little difference in mobility and time allocation to those who have never received a wheelchair. Thus we find little evidence that our results are driven by correlated unobservables that foster early selection into wheelchair ownership. We also carry out OLS, SUR, Tobit, and Heckman estimations on our data, and regardless of specification, regression results likewise point to large and significant economic gains from wheelchair access.

Seen through an economic lens, wheelchair allocation can be viewed as a technology shock to its beneficiaries. Jara-Diaz (2003) examines this technology change through the lens of an Activity Possibility Frontier. Wheelchairs push the technological feasibility constraint outward and enable a person who is disabled freedom to participate in income-generating activities, recalling Sen’s (1999) notion of “development as freedom.”

Because our results reveal impacts in only one region of one country, they invite other studies using different methodologies and within different populations to assess external validity. We would also encourage new studies to examine economic impacts of assistive devices, procedures, and medications for other types of disabilities such as vision correction, hearing loss, cleft palate surgery, speech disorders, and mental illness, treatment for some of which may be relatively cost effective, yet unavailable to many in the developing world. 
Although randomization of assistive devices that are known to be effective at mitigating impairment from disabilities is widely viewed as unethical, further research through quasiexperimental data, studying economic impacts where allocation of assistive devices was the product of some kind of clear eligibility rule or rollout pattern, would be helpful to ascertaining external validity of our study. Replication of results in other contexts in the developing world and across different types of disabilities would further solidify what we find to be extensive impacts from addressing the tangible needs of the physically disabled, many among the poorest of the world's poor. From a sustainability and cost-benefit perspective, subsequent studies could also look at wheelchair charity distribution versus self-manufacturing to ascertain the viability and potential scalability of various options.

There are hints in the literature that there exists a vast desire for economic participation among those with a disability that can be unleashed through the proper provision of assistive devices. Ali et al. (2010) find that people with disabilities are as likely as those without disabilities to express the desire for employment, but are less likely to be actively looking for a job. Metts (2004) and Awan (2012) measure the potential economic gains that countries like Ethiopia can experience if disabilities are properly addressed. Wheelchairs and other assistive devices may serve as a catalyst for the poor living with disabilities, giving these individuals both a hope and means for providing for themselves and their families, allowing them to live with greater dignity as they participate more fully in their economy and society. 


\section{References}

Ali, M., Schur, L., and Blanck, P. 2011 . What Types of Jobs Do People with Disabilities Want?. Journal Of Occupational Rehabilitation,21(2), 199-2 10. doi:10.1007/s 10926-0109266-0

Awan, H., Malik, S., and Khan, N. 2012. The Economic Burden of Blindness in Pakistan: A Socio-Economic and Policy Imperative for Poverty Reduction Strategies. Indian Journal Of Ophthalmology, 60(5), 358-364. doi:10.4103/0301-4738.100527

Becker, G. S. 1965. A Theory of the Allocation of Time. Economic Journal, 75, 493-517.

Borg, J., Ostergren, P., Larsson, S., Rahman, A., Bari, N., and Khan, A. 2012. Assistive Technology Use is Associated with Reduced Capability Poverty: A Cross-Sectional Study in Bangladesh. Disability and Rehabilitation. Assistive Technology, 7(2), 112-121.

Daher, H., and Flessa, S. 2010. Microfinance as a Tool for Financing Medical Devices in Syria. An Assessment of Needs and a Call for Further Research. Journal of Public Health 18(2), 189.

Diaz, S. 2003. On the Goods-Activities Technical Relations in the Time Allocation Theory. Transportation. 30, 245-260.

Gronau, R. 1986. Home Production- a Survey. Handbook of Labour Economy. 19: 1-17.

Imbens, G. 2004. Nonparametric Estimation of Average Treatment Effects Under Exogeneity: A Review. Review of Economics and Statistics. 86(1): 4-29

Khandker, S. R., G. B. Koolwal and H. A. Samad 2010. Handbook on Impact Evaluation: Quantitative Methods and Practices, World Bank, Washington, DC.

Owens, J., and Simonds, C. 2010. Beyond the Wheelchair: Development of Motorised Transport for People with Severe Mobility Impairments in Developing Countries. Disability and Rehabilitation: Assistive Technology, 5(4), 254.

Masuda, Y., Fortmann, L., Gugerty, M., Nilson, M., and Cook, J. 2012. Pictorial Approaches for Measuring Time Use in Rural Ethiopia. Social Indicators Research. 1-16.

Metts, R.. 2004. Disability and Development. World Bank.

Mizunoya, S., and Mitra, S. 2013. Is There a Disability Gap in Employment Rates in Developing Countries?. World Development, 4228-43. doi:10.1016/j.worlddev.2012.05.037.

Mukherjee, G., and Samanta, A. 2005. Wheelchair Charity: A Useless Benevolence in Community-Based Rehabilitation. Disability and Rehabilitation, 27(10), 591-596.

Pagán, R. 2013. Time Allocation of Disabled Individuals. Social Science and Medicine, 8480-93. 
Pearlman, J., Cooper, R. A., Zipfel, E., Cooper, R., and McCartney, M. 2006. Towards the Development of an Effective Technology Transfer Model of Wheelchairs to Developing Countries. Disability and Rehabilitation: Assistive Technology, 1(1/2), 103.

Rosenbaum, P. R., and Rubin, D. B. 1984. Reducing Bias in Observational Studies Using Subclassification on the Propensity Score. Journal of the American Statistical Association, (387).

Sen A. Development as Freedom. Oxford University Press; 1999.

Shore, S., and Juillerat, S. 2012. The Impact of a Low Cost Wheelchair on the Quality of Life of the Disabled in the Developing World. Medical Science Monitor: International Medical Journal of Experimental and Clinical Research, 18(9), CR533-CR542.

Shore, S. 2008. Use of an Economical Wheelchair in India and Peru: Impact on Health and Function. Medical Science Monitor, 14(12), PH71-PH79.

Sophie, M., Aleksandra, P., and Brandon, V. 2013. Disability and Poverty in Developing Countries: A Multidimensional Study. World Development, 41:1-18.

Steiner, P. M., and Cook, D. 2013. Matching and propensity scores. In T. D. Little (Ed.), The Oxford Handbook of Quantitative Methods (Vol.1): Foundations (pp. 237-259). New York, NY US: Oxford University Press.

Thomas, M. M., Hunt, A. A., Hurley, M. M., Robertson, S. S., and Carter, B. B. 2011 . Time-use Diaries are Acceptable to Parents with a Disabled Preschool Child and are Helpful in Understanding Families' Daily Lives. Child: Care, Health and Development, 37(2), 168174.

Tolerico, M., Ding, D., Cooper, R., Spaeth, D., Fitzgerald, S., Cooper, R., and Boninger, M. 2007. Assessing Mobility Characteristics and Activity Levels of Manual Wheelchair Users. Journal of Rehabilitation Research and Development, 44(4), 561-571.

World Health Organization (WHO). Disability and Rehabilitation on-line website at www.who.int/ncd/disability/.

Zellner, Arnold. 1962. An Efficient Method of Estimating Seemingly Unrelated Regressions and Tests for Aggregation Bias. Journal of the American Statistical Association, 57(298), 348-368. 
Figure 1. Time allocation survey

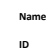

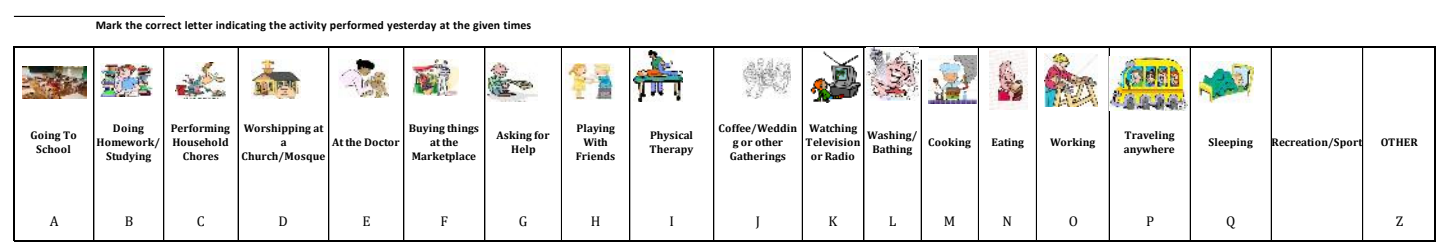

What Day Was Yesterday

1:00 AM

1:30 AM

2:00 AM

2:30 AM

3:00 AM

3:30 AM

4:00 AM

4:30 AM

5:00 AM

5:30 AM

6:00 AM

6:30 AM

7:00 AM

$7: 30 \mathrm{AM}$

8:00 AM

8:30 AM

9:00 AM
9:30 AM

10:00 AM

10:30 AM

11:00 AM

11:30 AM

12:00 PM

12:30 PM
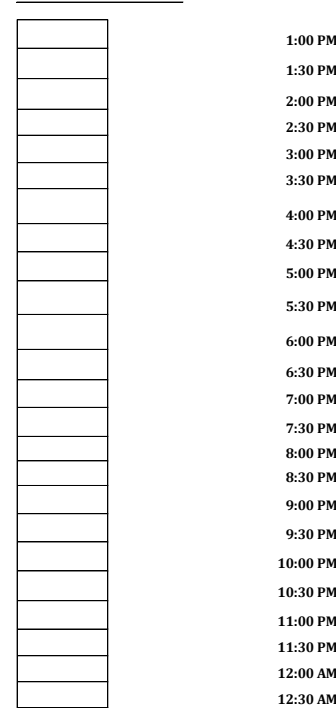

1:00 PM

1:30 PM

2:00 PM

2:30 PM

3:00 PM

3:30 PM

4:00 PM

4:30 PM

5:00 PM

5:30 PM

6.00 PM

6:30 PM

7:00 PM

7:30 PM

8:00 PM

8:30 PM

9:00 PM

9:30 PM

10:00 PM

10:30 PM

11:00 PM

11:30 PM

12:00 AM

12:30 AM

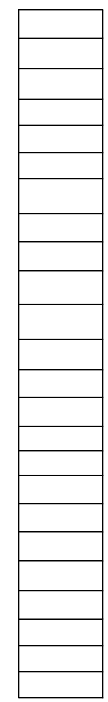

Figure 2. Time working

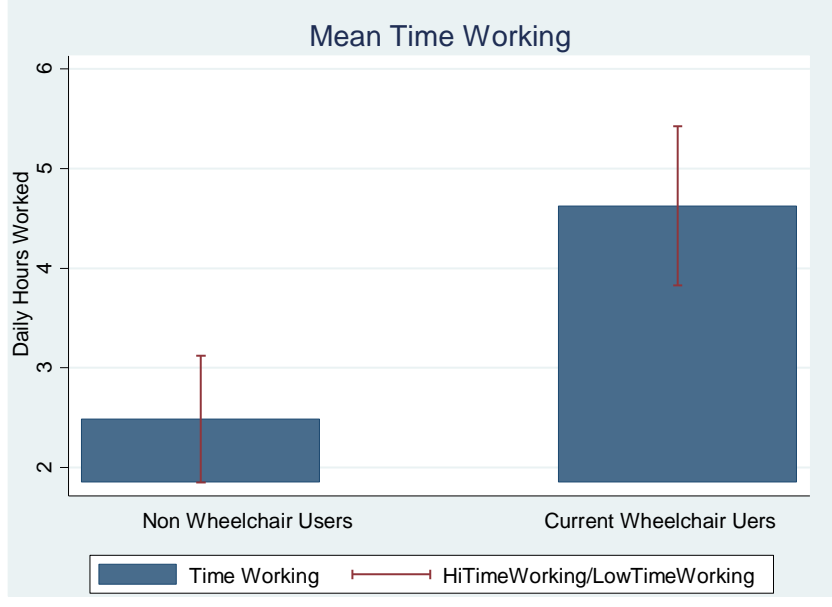

Figure 3. Kernel density time working

Kernel density estimate

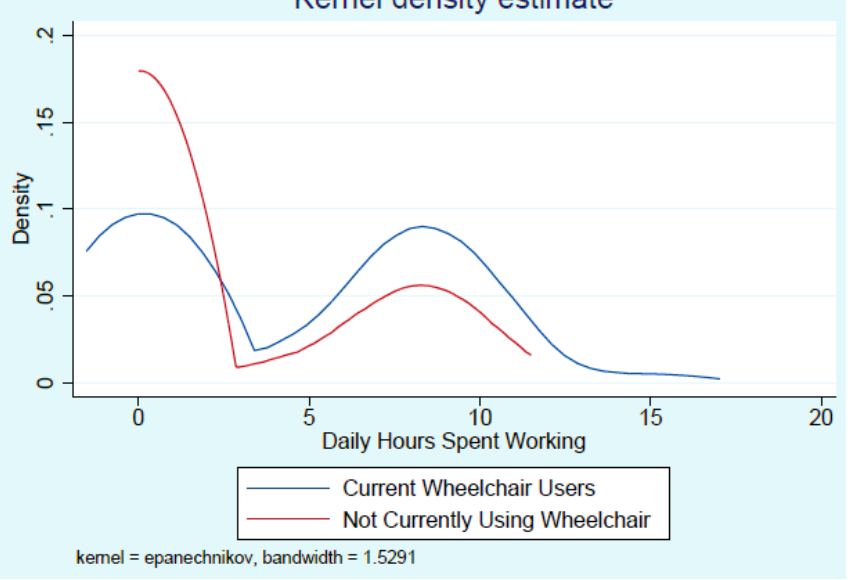


Figure 4. Weekly income

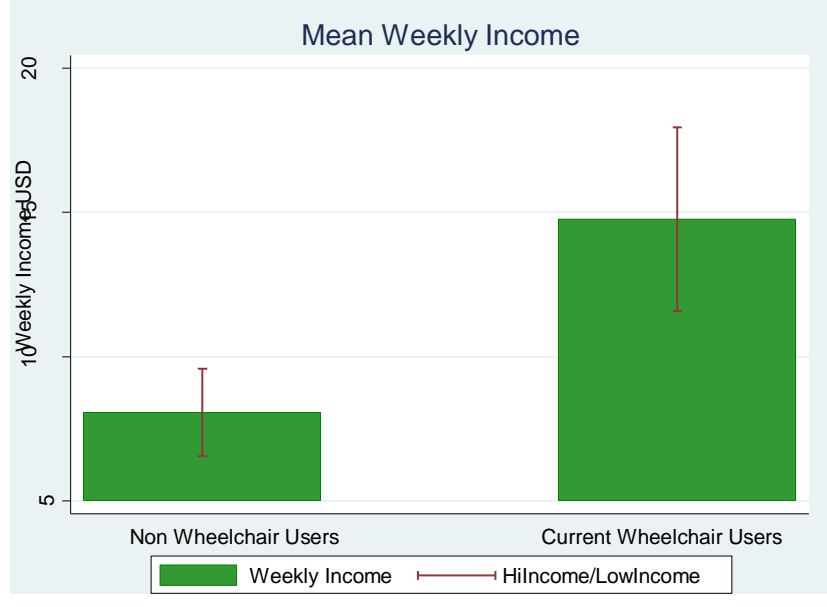

Figure 6. Farthest distance traveled

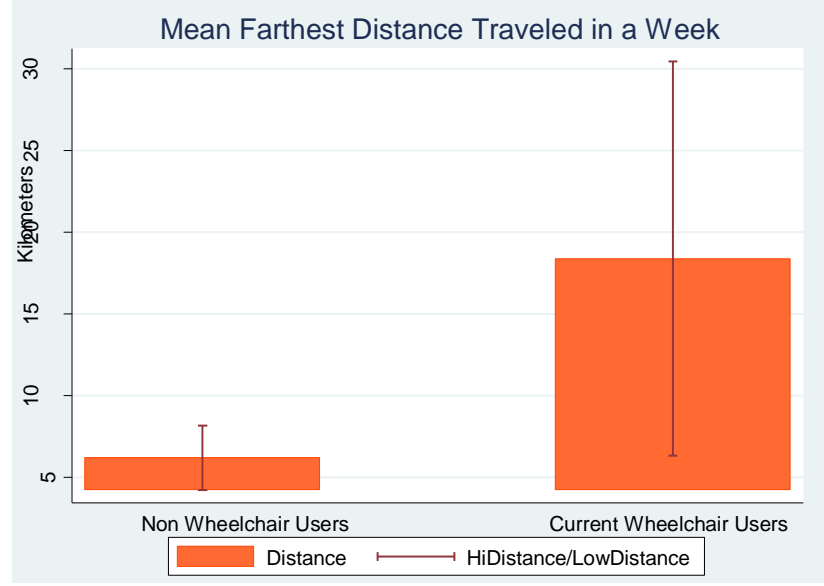

Figure 5. Kernel density weekly income

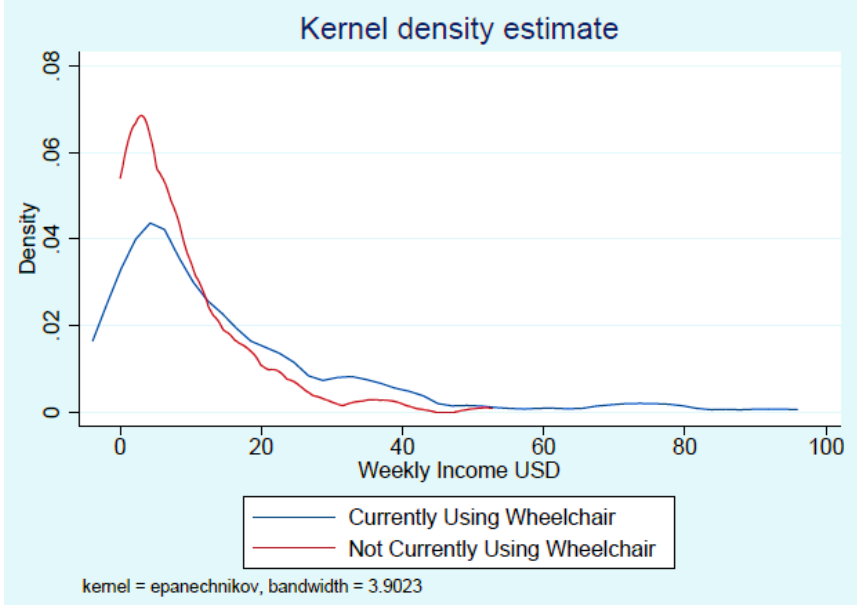

Figure 7. Kernel density farthest distance

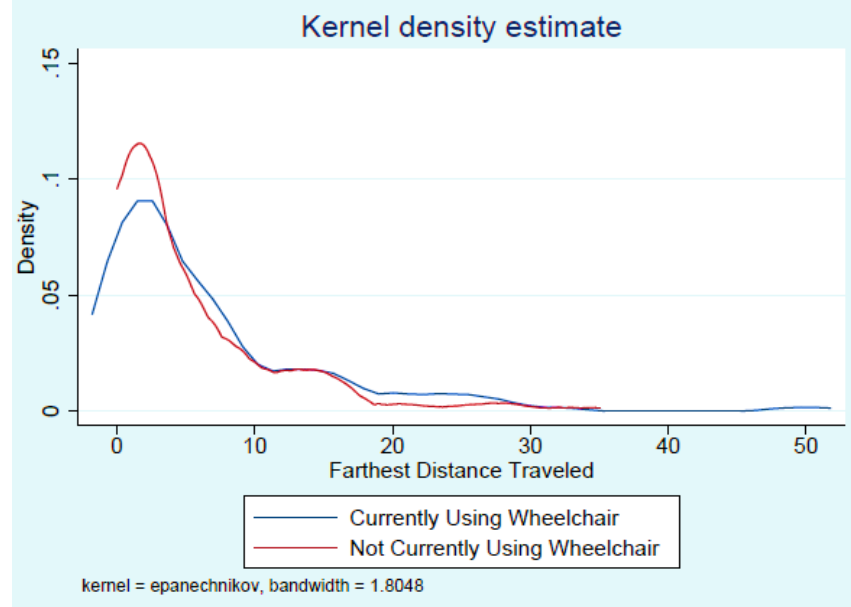


Table 1. Summary statistics

\begin{tabular}{|lllll|}
\hline Variable & Current w.c. user & Not current w.c. user & Difference & $p$-value \\
\hline Age & 35.9 & 37.28 & -1.38 & 0.419 \\
Children & 1.31 & 1.18 & 0.13 & 0.553 \\
Siblings & 4.11 & 3.95 & 0.16 & 0.673 \\
Parents Years of Schooling & 1.32 & 0.94 & 0.38 & 0.326 \\
Single & 0.41 & 0.50 & -0.087 & 0.162 \\
Married & 0.47 & 0.40 & 0.07 & 0.249 \\
War Victim Disability & 0.12 & 0.10 & 0.024 & 0.541 \\
Work Accident Disability & 0.13 & 0.14 & -0.004 & 0.935 \\
Polio Disability & 0.35 & 0.29 & 0.061 & 0.288 \\
Infection Disability & 0.12 & 0.086 & 0.038 & 0.313 \\
Orthodox Religion & 0.78 & 0.80 & -0.015 & 0.768 \\
Protestant Religion & 0.12 & 0.057 & 0.059 & $0.090^{*}$ \\
Muslim Religion & 0.066 & 0.12 & -0.055 & 0.131 \\
Years of Schooling & 6.01 & 4.21 & 1.8 & $0.0011^{* * * *}$ \\
Ambition & 0.835 & 0.70 & 0.135 & $0.0107^{* * *}$ \\
Farthest Distance Traveled in & & & & \\
Past Week & 18.84 & 6.28 & 0.69 & $0.0424^{* * *}$ \\
Days Left House in a Week & 5.08 & 4.39 & 2.14 & $0.000^{* * * *}$ \\
Time Spent Working & 4.63 & 2.49 & -1.4 & $0.0004^{* * * *}$ \\
Time Spent Begging & 0.74 & 2.14 & 6.693 & $0.0001^{* * * *}$ \\
Weekly Income & 14.76 & 8.07 & 0.202 & $0.0010^{* * * *}$ \\
Probability of Having a Job & 0.645 & 0.443 & & \\
\hline
\end{tabular}


Table 2. Covariate matching current wheelchair users to non-wheelchair users

\begin{tabular}{cccccc}
\hline \multirow{2}{*}{ VARIABLES } & Time working & Weekly income & $(3)$ & $(4)$ & $(5)$ \\
ETT & $1.745^{* * *}$ & $6.225^{* * * *}$ & $0.151^{* *}$ & 11.176 & 0.463 \\
& $(0.586)$ & $(2.004)$ & $(0.067)$ & $(6.883)$ & $(0.369)$ \\
ATE & $1.862^{* * *}$ & $5.739^{* * *}$ & $0.175^{* * *}$ & $14.474^{*}$ & $0.589^{*}$ \\
& $(0.557)$ & $(1.779)$ & $(0.063)$ & $(7.606)$ & $(0.345)$
\end{tabular}

$\begin{array}{llllll}\text { Observations } & 260 & 260 & 260 & 260 & 260\end{array}$

Notes: Matching covariates are: age, gender, education, time disabled, siblings, religion, disability type. Standard errors are in parentheses. Weekly income shown as \$USD, employed is the probability of reporting having a job. Time spent working given in hours per day, distance traveled in the past week, given in kilometers. *** $\mathrm{p}<0.01$, ** $\mathrm{p}<0.05,{ }^{*} \mathrm{p}<0.1$.

Table 3. PSM on outcome variables

\begin{tabular}{lccccc}
\hline & $(1)$ & $(2)$ & $(3)$ & $(4)$ & $(5)$ \\
VARIABLES & Time Working & Weekly income & Employed & Farthest distance & Days left house \\
\hline ATT & $2.202^{* * *}$ & $7.439^{* * *}$ & $0.207^{* * *}$ & $12.372^{* * *}$ & 0.048 \\
& $(0.720)$ & $(2.084)$ & $(0.089)$ & $(6.430)$ & $(0.137)$ \\
Observations & 186 & 186 & 186 & 186 & 186 \\
\hline
\end{tabular}

Notes: Matching covariates are: age, gender, education, time disabled, siblings, religion, disability type. Standard errors are in parentheses. Weekly income shown as \$USD, employed is the probability of reporting having a job. Time spent working given in hours per day, distance traveled in the past week, given in kilometers. $* * * \mathrm{p}<0.01$, ** $\mathrm{p}<0.05, * \mathrm{p}<0.1$. 
Table 4. Estimation of propensity scores

\begin{tabular}{lc}
\hline & $(1)$ \\
VARIABLES & Props.-score \\
\hline Age & $-0.02214^{*}$ \\
& $(0.01267)$ \\
Gender & $0.72342^{* *}$ \\
& $(0.35887)$ \\
Siblings & 0.00083 \\
& $(0.04498)$ \\
Education & $0.08442^{* * *}$ \\
& $(0.03106)$ \\
Orthodox & 0.56465 \\
& $(1.30113)$ \\
Protestant & 1.12870 \\
& $(1.35781)$ \\
Muslim & -0.08715 \\
Other Religion & $(1.36915)$ \\
& 1.38563 \\
Polio & $(1.80413)$ \\
& 0.93549 \\
Other Disability & $(1.16492)$ \\
& 0.76313 \\
War/Work/Infection & $(1.17697)$ \\
& 1.30937 \\
Natural Disability & $(1.16072)$ \\
& 0.84095 \\
Time Disabled & $(1.20120)$ \\
& $0.03406 * *$ \\
Constant & $(0.01454)$ \\
Observations & -2.64315 \\
Notes: Standard errors are in parentheses. *** p<0.01, & $(1.76620)$ \\
& \\
& \\
&
\end{tabular}


Table 5. Covariate matching current wheelchair users to past wheelchair users

\begin{tabular}{|c|c|c|c|c|c|c|}
\hline & (1) & (2) & (3) & $(4)$ & $(5)$ & (6) \\
\hline VARIABLES & Weekly income & Employed & $\begin{array}{l}\text { Time } \\
\text { working }\end{array}$ & $\begin{array}{l}\text { Time } \\
\text { begging }\end{array}$ & $\begin{array}{l}\text { Farthest } \\
\text { distance }\end{array}$ & $\begin{array}{l}\text { Days left } \\
\text { house }\end{array}$ \\
\hline \multirow[t]{2}{*}{ ATT } & $4.305^{*}$ & $0.151^{*}$ & $1.767^{*} *$ & $-1.502^{*} * * *$ & 11.932 & 0.097 \\
\hline & $(2.559)$ & $(0.088)$ & $(0.748)$ & $(0.488)$ & $(8.571)$ & $(0.445)$ \\
\hline \multirow[t]{2}{*}{ ATE } & 3.726 & $0.146^{*}$ & $1.763^{*} *$ & $-1.261^{\text {**** }}$ *ै & 14.275 & 0.265 \\
\hline & $(2.351)$ & $(0.084)$ & $(0.722)$ & $(0.467)$ & $(9.497)$ & $(0.429)$ \\
\hline Observations & 179 & 179 & 179 & 179 & 179 & 179 \\
\hline
\end{tabular}

Notes: Matching current wheelchair users to those who used to use a wheelchair in the past. Matching covariates are: age, gender, education, ambition, siblings, religion, disability, time disabled. An ambition dummy is added to the matching covariates. Standard errors are in parentheses. Weekly income shown as \$USD, employed is the probability of reporting having a job. Time spent working given in hours per day, distance traveled in the past week, given in kilometers. ${ }^{* * *} \mathrm{p}<0.01$, $* * \mathrm{p}<0.05,{ }^{*} \mathrm{p}<0.1$.

Table 6. Covariate matching past wheelchair users to never-wheelchair users

\begin{tabular}{|c|c|c|c|c|c|c|}
\hline VARIABLES & $\begin{array}{l}(1) \\
\text { Weekly income }\end{array}$ & $\begin{array}{l}(2) \\
\text { Employed }\end{array}$ & $\begin{array}{l}(3) \\
\text { Time } \\
\text { working }\end{array}$ & $\begin{array}{l}(4) \\
\text { Time } \\
\text { begging }\end{array}$ & $\begin{array}{l}(5) \\
\text { Farthest } \\
\text { distance }\end{array}$ & $\begin{array}{l}(6) \\
\text { Days left } \\
\text { house }\end{array}$ \\
\hline ATT & $\begin{array}{l}3.248^{*} \\
(1.936)\end{array}$ & $\begin{array}{l}-0.004 \\
(0.102)\end{array}$ & $\begin{array}{l}-.963 \\
(0.807)\end{array}$ & $\begin{array}{l}-.097 \\
(0.644)\end{array}$ & $\begin{array}{l}-2.892 \\
(3.589)\end{array}$ & $\begin{array}{l}0.479 \\
(0.622)\end{array}$ \\
\hline ATE & $\begin{array}{l}4.585^{* * * *} \\
(1.669)\end{array}$ & $\begin{array}{l}0.061 \\
(0.088)\end{array}$ & $\begin{array}{l}0.234 \\
(0.715)\end{array}$ & $\begin{array}{l}-0.272 \\
(0.598)\end{array}$ & $\begin{array}{l}-1.477 \\
(2.593)\end{array}$ & $\begin{array}{l}(0.637) \\
(0.513)\end{array}$ \\
\hline Observations & 139 & 139 & 139 & 139 & 139 & 139 \\
\hline
\end{tabular}

Notes: Matching current wheelchair users to those who used to use a wheelchair in the past. Matching covariates are: age, gender, education, ambition, siblings, religion, disability, time disabled. An ambition dummy is added to the matching covariates. Standard errors are in parentheses. Weekly income shown as \$USD, employed is the probability of reporting having a job. Time spent working given in hours per day, distance traveled in the past week, given in kilometers. ${ }^{*} * * \mathrm{p}<0.01$, ** $\mathrm{p}<0.05, * \mathrm{p}<0.1$. 
Table 7. Rosenbaum bounds for weekly income

\begin{tabular}{|l|l|l|l|l|l|l|}
\hline Gamma & sig+ & sig- & t-hat+ & t-hat- & CI+ & CI- \\
\hline 1 & 0.003529 & 0.003529 & 3.81579 & 3.81579 & 1.02947 & 7.26737 \\
1.1 & 0.012459 & 0.000812 & 3.15789 & 4.60526 & 0.394737 & 8.10526 \\
1.2 & 0.033252 & 0.000175 & 2.57895 & 5.26316 & -0.174474 & 8.75868 \\
1.3 & 0.07172 & 0.000036 & 1.98342 & 5.98789 & -0.751052 & 9.44737 \\
1.4 & 0.131173 & $7.00 \mathrm{E}-06$ & 1.52631 & 6.47789 & -1.15789 & 10.1413 \\
1.5 & 0.210803 & $1.30 \mathrm{E}-06$ & 1.05263 & 7.19211 & -1.64368 & 10.7603 \\
1.6 & 0.305807 & $2.50 \mathrm{E}-07$ & 0.736842 & 7.68421 & -2.02632 & 11.3684 \\
1.7 & 0.408916 & $4.40 \mathrm{E}-08$ & 0.303685 & 8.19842 & -2.44737 & 12.1458 \\
1.8 & 0.512382 & $7.90 \mathrm{E}-09$ & $-1.10 \mathrm{E}-06$ & 8.55263 & -2.84658 & 12.6097 \\
1.9 & 0.60961 & $1.40 \mathrm{E}-09$ & -0.394737 & 9.10947 & -3.215 & 13.1579 \\
2 & 0.696046 & $2.40 \mathrm{E}-10$ & -0.722631 & 9.41447 & -3.55263 & 13.8158 \\
2.1 & 0.769341 & $4.00 \mathrm{E}-11$ & -0.961579 & 9.86184 & -3.84868 & 14.3947 \\
2.2 & 0.829018 & $6.80 \mathrm{E}-12$ & -1.27526 & 10.2632 & -4.03947 & 14.7368 \\
2.3 & 0.875933 & $1.10 \mathrm{E}-12$ & -1.52632 & 10.6132 & -4.28947 & 15.3613 \\
2.4 & 0.911703 & $1.90 \mathrm{E}-13$ & -1.84211 & 11.0526 & -4.60526 & 15.6579 \\
2.5 & 0.938255 & $3.10 \mathrm{E}-14$ & -2.00658 & 11.3158 & -4.86842 & 16.2105 \\
\hline
\end{tabular}


Table 8. Rosenbaum bounds for time working

\begin{tabular}{|c|c|c|c|c|c|c|}
\hline Gamma & $\operatorname{sig}+$ & sig- & t-hat+ & t-hat- & $\mathrm{CI}+$ & CI- \\
\hline 1.0 & 0.000352 & 0.000352 & 2.25 & 2.25 & 0.5 & 3.5 \\
\hline 1.1 & 0.001496 & 0.000068 & 1.75 & 2.75 & 0.25 & 3.75 \\
\hline 1.2 & 0.004778 & 0.000013 & 1.25 & 3 & $-4.7 \mathrm{OE}-07$ & 4 \\
\hline 1.3 & 0.012257 & $2.30 \mathrm{E}-06$ & 1.25 & 3.25 & $-4.7 \mathrm{OE}-07$ & 4 \\
\hline 1.4 & 0.026491 & 4.00E-07 & 0.75 & 3.25 & $-4.7 \mathrm{OE}-07$ & 4.25 \\
\hline 1.5 & 0.049961 & $6.80 \mathrm{E}-08$ & 0.5 & 3.5 & $-4.70 \mathrm{E}-07$ & 4.25 \\
\hline 1.6 & 0.084429 & $1.10 \mathrm{E}-08$ & 0.250001 & 3.5 & $-4.7 \mathrm{OE}-07$ & 4.5 \\
\hline 1.7 & 0.130469 & 1.90E-09 & $4.70 \mathrm{O}-07$ & 3.75 & -0.25 & 4.5 \\
\hline 1.8 & 0.18732 & $3.10 \mathrm{E}-10$ & $-4.70 \mathrm{E}-07$ & 4 & -0.5 & 4.5 \\
\hline 1.9 & 0.253055 & $5.10 \mathrm{E}-11$ & $-4.70 \mathrm{E}-07$ & 4 & -0.749999 & 4.75 \\
\hline 2.0 & 0.324956 & $8.30 \mathrm{E}-12$ & $-4.70 \mathrm{E}-07$ & 4 & -0.75 & 4.75 \\
\hline 2.1 & 0.399964 & $1.30 \mathrm{E}-12$ & $-4.70 \mathrm{E}-07$ & 4.25 & -1 & 5 \\
\hline 2.2 & 0.475096 & $2.10 \mathrm{E}-13$ & $-4.70 \mathrm{E}-07$ & 4.25 & -1 & 5 \\
\hline 2.3 & 0.547753 & $3.40 \mathrm{E}-14$ & $-4.70 \mathrm{E}-07$ & 4.25 & -1.25 & 5.25 \\
\hline 2.4 & 0.615898 & $5.30 \mathrm{E}-15$ & $-4.70 \mathrm{E}-07$ & 4.25 & -1.25 & 5.25 \\
\hline 2.5 & 0.678123 & $8.90 \mathrm{E}-16$ & $-4.70 \mathrm{E}-07$ & 4.5 & -1.5 & 5.5 \\
\hline
\end{tabular}


Table 9. Rosenbaum bounds for farthest distance

\begin{tabular}{|l|l|l|l|l|l|l|}
\hline Gamma & sig+ & sig- & t-hat+ & t-hat- & CI+ & CI- \\
\hline 1.0 & 0.384013 & 0.384013 & 0.25 & 0.25 & -1.25 & 2 \\
1.1 & 0.563382 & 0.226586 & -0.05 & 0.65 & -1.6 & 2.4 \\
1.2 & 0.717278 & 0.121576 & -0.5 & 1 & -2 & 2.75 \\
1.3 & 0.830889 & 0.060249 & -0.75 & 1.4 & -2.25 & 3 \\
1.4 & 0.905503 & 0.027948 & -1 & 1.5 & -2.5 & 3.5 \\
1.5 & 0.950168 & 0.01227 & -1.25 & 2 & -2.85 & 3.75 \\
1.6 & 0.974983 & 0.005145 & -1.5 & 2 & -3 & 4 \\
1.7 & 0.987956 & 0.002075 & -1.6 & 2.5 & -3.25 & 4.5 \\
1.8 & 0.994406 & 0.00081 & -2 & 2.5 & -3.5 & 4.825 \\
1.9 & 0.99748 & 0.000307 & -2 & 2.95 & -3.6 & 5.25 \\
2.0 & 0.998895 & 0.000114 & -2.25 & 3 & -4 & 5.5 \\
2.1 & 0.999526 & 0.000041 & -2.5 & 3.25 & -4.05 & 6 \\
2.2 & 0.999801 & 0.000015 & -2.5 & 3.5 & -4.5 & 6.5 \\
2.3 & 0.999918 & $5.20 \mathrm{E}-06$ & -2.6 & 3.65 & -4.5 & 6.9 \\
2.4 & 0.999967 & $1.80 \mathrm{E}-06$ & -3 & 3.95 & -4.85 & 7 \\
2.5 & 0.999987 & $6.10 \mathrm{E}-07$ & -3 & 4 & -5 & 7.5 \\
\hline
\end{tabular}


Table 10. Seemingly unrelated regression results for time allocation

\begin{tabular}{|c|c|c|c|c|}
\hline VARIABLES & $\begin{array}{c}(1) \\
\text { Time working }\end{array}$ & $\begin{array}{c}(2) \\
\text { Time begging }\end{array}$ & $\begin{array}{c}(3) \\
\text { Time social }\end{array}$ & $\begin{array}{c}(4) \\
\text { Time out of house }\end{array}$ \\
\hline Current Wheelchair & $\begin{array}{c}1.93554^{* * * * *} \\
(0.60932)\end{array}$ & $\begin{array}{c}-1.19695^{* * * *} \\
(0.42895)\end{array}$ & $\begin{array}{c}-0.71220^{*} \\
(0.40777)\end{array}$ & $\begin{array}{c}0.17886 \\
(0.33128)\end{array}$ \\
\hline $\begin{array}{l}\text { Past (Not Current) } \\
\text { Wheelchair User }\end{array}$ & -0.21518 & -0.05499 & -0.74379 & 0.06724 \\
\hline Age & $\begin{array}{c}(0.70368) \\
0.24582^{* *} \\
(0.11598)\end{array}$ & $\begin{array}{l}(0.49538) \\
-0.06278 \\
(0.08165)\end{array}$ & $\begin{array}{l}(0.47092) \\
-0.12763 \\
(0.07762)\end{array}$ & $\begin{array}{l}(0.38258) \\
-0.07372 \\
(0.06306)\end{array}$ \\
\hline Age Squared & $\begin{array}{c}-0.00368^{* * * *} \\
(0.00126)\end{array}$ & $\begin{array}{c}0.00107 \\
(0.00089)\end{array}$ & $\begin{array}{c}0.00125 \\
(0.00084)\end{array}$ & $\begin{array}{c}0.00074 \\
(0.00069)\end{array}$ \\
\hline Education & $\begin{array}{c}0.01512 \\
(0.05735)\end{array}$ & $\begin{array}{c}-0.19196^{* * * *} \\
(0.04037)\end{array}$ & $\begin{array}{c}0.09773^{* * *} \\
(0.03838)\end{array}$ & $\begin{array}{c}0.02499 \\
(0.03118)\end{array}$ \\
\hline Time Disabled & $\begin{array}{c}0.02073 \\
(0.02801)\end{array}$ & $\begin{array}{c}0.00536 \\
(0.01972)\end{array}$ & $\begin{array}{l}-0.01400 \\
(0.01875)\end{array}$ & $\begin{array}{l}0.02723^{*} \\
(0.01523)\end{array}$ \\
\hline Single & $\begin{array}{l}2.79761^{*} \\
(1.57922)\end{array}$ & $\begin{array}{c}0.83950 \\
(1.11174)\end{array}$ & $\begin{array}{c}0.07441 \\
(1.05685)\end{array}$ & $\begin{array}{c}1.03326 \\
(0.85860)\end{array}$ \\
\hline Married & $\begin{array}{r}3.46677^{* * *} \\
(1.50867)\end{array}$ & $\begin{array}{c}0.22801 \\
(1.06207)\end{array}$ & $\begin{array}{c}0.58563 \\
(1.00963)\end{array}$ & $\begin{array}{c}1.04474 \\
(0.82024)\end{array}$ \\
\hline Divorced & $\begin{array}{c}1.70524 \\
(1.73173)\end{array}$ & $\begin{array}{c}2.91536^{* *} \\
(1.21910)\end{array}$ & $\begin{array}{c}0.36315 \\
(1.15891)\end{array}$ & $\begin{array}{c}0.61320 \\
(0.94152)\end{array}$ \\
\hline Disability & $\mathrm{X}$ & $\mathrm{X}$ & $\mathrm{X}$ & $\mathrm{X}$ \\
\hline Religion & $\mathrm{X}$ & $\mathrm{X}$ & $\mathrm{X}$ & $\mathrm{X}$ \\
\hline Observations & 260 & 260 & 260 & 260 \\
\hline R-squared & 0.20090 & 0.30069 & 0.12153 & 0.11468 \\
\hline
\end{tabular}

Notes: Standard errors are in parentheses. Time allocation given in number of 60 minute intervals per day. *** $\mathrm{p}<0.01,{ }^{* *} \mathrm{p}<0.05,{ }^{*} \mathrm{p}<0.1$. 
Table 11. Weekly income results

$\begin{array}{cccc}(1) & (2) & (3) & (4) \\ \text { OLS } & \text { Tobit } & \text { Heckman }\end{array}$

\begin{tabular}{|c|c|c|c|c|}
\hline VARIABLES & Weekly income & Weekly income & Weekly income & Select \\
\hline \multirow[t]{2}{*}{ Current Wheelchair } & $7.87 \mathrm{O}^{* * * *}$ & $9.447^{*} * * *$ & 7.790 & \\
\hline & $(2.047)$ & $(2.282)$ & $(6.406)$ & \\
\hline Past (Not Current) & 1.862 & 2.957 & 1.311 & \\
\hline \multicolumn{5}{|l|}{ Wheelchair } \\
\hline \multirow{3}{*}{ Age } & $(2.397)$ & $(2.666)$ & $(7.552)$ & \\
\hline & $0.729^{*}$ & $0.849^{*}$ & 0.781 & \\
\hline & $(0.401)$ & $(0.444)$ & $(1.255)$ & \\
\hline \multirow[t]{2}{*}{ Age Squared } & $-0.009^{* *}$ & $-0.010^{*} *$ & -0.009 & \\
\hline & $(0.004)$ & $(0.005)$ & $(0.014)$ & \\
\hline \multirow[t]{2}{*}{ Children } & $-1.235^{*}$ & $-1.494^{*}$ & & $0.098^{*}$ \\
\hline & $(0.696)$ & $(0.781)$ & & $(0.058)$ \\
\hline \multirow[t]{2}{*}{ Parents Education } & $0.624^{* * *}$ & $0.643^{*}$ & 1.020 & \\
\hline & $(0.301)$ & $(0.335)$ & (0.990) & \\
\hline \multirow[t]{2}{*}{ Education } & 0.072 & 0.058 & 0.060 & \\
\hline & $(0.206)$ & $(0.228)$ & $(0.646)$ & \\
\hline \multirow[t]{2}{*}{ Time Disabled } & $0.337 * * *$ & $0.411^{* * * *}$ & 0.307 & \\
\hline & (0.096) & $(0.107)$ & (0.302) & \\
\hline \multirow[t]{2}{*}{ Single } & 5.298 & 8.641 & 0.548 & \\
\hline & $(3.518)$ & $(6.337)$ & $(20.085)$ & \\
\hline \multirow[t]{2}{*}{ Married } & -1.381 & 1.065 & -5.220 & \\
\hline & $(3.883)$ & $(6.382)$ & $(20.358)$ & \\
\hline \multirow[t]{2}{*}{ Constant } & $-30.846^{* *}$ & $-34.295^{* *}$ & -34.505 & O.833*** \\
\hline & $(15.180)$ & $(15.590)$ & $(54.385)$ & (0.110) \\
\hline Live With & $\mathrm{X}$ & $\mathrm{X}$ & $\mathrm{X}$ & $\mathrm{X}$ \\
\hline Disability & $\mathrm{X}$ & $\mathrm{X}$ & $\mathrm{X}$ & $\mathrm{X}$ \\
\hline Religion & $\mathrm{X}$ & $\mathrm{X}$ & $\mathrm{X}$ & $\mathrm{X}$ \\
\hline Observations & 260 & 260 & 260 & 260 \\
\hline R-squared & 0.300 & & & \\
\hline
\end{tabular}


Table 12. Farthest distance traveled in the past seven days

\begin{tabular}{|c|c|c|c|c|}
\hline VARIABLES & $\begin{array}{c}(1) \\
\text { OLS } \\
\text { Farthest distance }\end{array}$ & $\begin{array}{c}(2) \\
\text { Tobit } \\
\text { Farthest distance }\end{array}$ & $\begin{array}{c}(3) \\
\text { Heckman } \\
\text { Farthest distance }\end{array}$ & $\begin{array}{c}(4) \\
\text { Select }\end{array}$ \\
\hline Current Wheelchair & $\begin{array}{l}12.954^{*} \\
(7.582)\end{array}$ & $\begin{array}{l}11.045 \\
(7.850)\end{array}$ & $\begin{array}{c}15.663 \\
(39.625)\end{array}$ & \\
\hline $\begin{array}{l}\text { Past (Not Current) } \\
\text { Wheelchair }\end{array}$ & -3.627 & -9.329 & -1.336 & \\
\hline Age & $\begin{array}{c}(8.899) \\
1.213 \\
(1.457)\end{array}$ & $\begin{array}{c}(9.264) \\
1.372 \\
(1.529)\end{array}$ & $\begin{array}{c}(47.192) \\
1.609 \\
(7.886)\end{array}$ & \\
\hline Age Squared & $\begin{array}{l}-0.016 \\
(0.016)\end{array}$ & $\begin{array}{l}-0.019 \\
(0.017)\end{array}$ & $\begin{array}{l}-0.020 \\
(0.087)\end{array}$ & \\
\hline Children & $\begin{array}{l}2.408 \\
(2.566)\end{array}$ & $\begin{array}{l}2.592 \\
(2.650)\end{array}$ & & $\begin{array}{c}0.040 \\
(0.064)\end{array}$ \\
\hline Parents Education & $\begin{array}{l}-0.757 \\
(1.119)\end{array}$ & $\begin{array}{l}-0.668 \\
(1.155)\end{array}$ & $\begin{array}{l}-0.864 \\
(5.826)\end{array}$ & \\
\hline Education & $\begin{array}{c}0.426 \\
(0.769)\end{array}$ & $\begin{array}{c}0.265 \\
(0.800)\end{array}$ & $\begin{array}{c}0.356 \\
(4.104)\end{array}$ & \\
\hline Time Disabled & $\begin{array}{l}-0.189 \\
(0.360)\end{array}$ & $\begin{array}{l}-0.071 \\
(0.376)\end{array}$ & $\begin{array}{l}-0.314 \\
(1.960)\end{array}$ & \\
\hline Constant & $\begin{array}{l}-29.725 \\
(53.287)\end{array}$ & $\begin{array}{l}-11.767 \\
(46.743)\end{array}$ & $\begin{array}{c}59.263 \\
(390.125)\end{array}$ & $\begin{array}{c}1.115^{* * * *} \\
(0.123)\end{array}$ \\
\hline Live With & $\mathrm{X}$ & $\mathrm{X}$ & $\mathrm{X}$ & $\mathrm{X}$ \\
\hline Disability & $\mathrm{X}$ & $\mathrm{X}$ & $\mathrm{X}$ & $\mathrm{X}$ \\
\hline Religion & $\mathrm{X}$ & $\mathrm{X}$ & $\mathrm{X}$ & $\mathrm{X}$ \\
\hline $\begin{array}{l}\text { Observations } \\
\text { R-squared }\end{array}$ & $\begin{array}{c}260 \\
0.092\end{array}$ & 260 & 261 & 261 \\
\hline
\end{tabular}

Table 13. Cost benefit analysis of a wheelchair

\begin{tabular}{llllll}
\hline Year & Costs & Benefits & Total benefits & Discount factor & Present value \\
\hline 0 & $\$ 500$ & $\$ 324$ & $(\$ 176)$ & 1.00 & $-\$ 176.04$ \\
1 & $\$ 20$ & $\$ 324$ & $\$ 304$ & 0.91 & $\$ 277.64$ \\
2 & $\$ 20$ & $\$ 324$ & $\$ 304$ & 0.83 & $\$ 251.24$ \\
\hline \multicolumn{7}{l}{ Discount rate $=10 \%$} \\
\multicolumn{7}{l}{ Internal rate of return = 122\% } \\
\multicolumn{5}{l}{ Note: Uses weekly income impact estimate in Table 2 of $\$ 6.23$ and a wheelchair cost of $\$ 500}$.
\end{tabular}

